\title{
Clinical, physiological and radiological features of asthma with incomplete reversibility of airflow obstruction compared with those of COPD
}

\author{
Louis-Philippe Boulet MD FRCPC, Hélène Turcotte MSc, Catherine Hudon BSc, \\ Guy Carrier MD FRCPC, François Maltais MD
}

Unité de Recherche, Centre de Pneumologie de l'Hôpital Laval, Université Laval, Sainte-Foy, Québec

L-P Boulet, H Turcotte, C Hudon, G Carrier, F Maltais. Clinical, physiological and radiological features of asthma with incomplete reversibility of airflow obstruction compared with those of COPD. Can Respir J 1998;5(4):270-277.

OBJECTIVES: To compare clinical features, pulmonary function and high-resolution computed chest tomography (HRCT) findings of asthmatic patients with a component of incomplete reversibility of airflow obstruction (AIRAO) with those of patients with smoking-induced chronic obstructive pulmonary disease (COPD).

METHODS: Thirteen patients with COPD (six males and seven females, mean age 59 years, mean smoking 50.5 packyears) and 14 patients with AIRAO (six males and eight females, mean age 52 years) despite optimal treatment, with no significant smoking history (mean 1.5 pack-years) and no significant environmental exposure or any other respiratory disease, were studied. Patients had respiratory questionnaires, pulmonary function tests, allergy skin-prick tests and an HRCT to evaluate possible parenchymal or bronchial abnormalities. Eight patients in each group also had exercise tests. All patients were stable at the time of the study.

RESULTS: As expected, atopy was more prevalent in AIRAO $(n=13)$ than in COPD $(n=1)$ patients. Mean forced expiratory volume in $1 \mathrm{~s}\left(\mathrm{FEV}_{1}\right)$ and forced vital capacity (percentage of predicted value) were $39 \%$ and $61 \%$, respec- tively, in COPD patients and $49 \%$ and $71 \%$, respectively, in AIRAO patients; $\mathrm{FEV}_{1}$ improved by $18 \%$ in COPD patients and and by $22 \%$ in AIRAO patients after use of inhaled salbutamol. Mean functional residual capacity was greater in COPD patients than in AIRAO patients (178\% versus $144 \%$ of the predicted value), while the mean carbon monoxide diffusing capacity of the lungs (DLCO) was lower in COPD patients than in AIRAO patients $(62 \%$ versus $89 \%$ of the predicted value). Exercise tolerance was similar in both groups, as were postexercise changes in arterial oxygen pressure $\left(\mathrm{PaO}_{2}\right)$. Emphysematous changes were observed in COPD patients and AIRAO patients who had evaluable HRCTs (10 versus two patients, although very mild in asthma), bronchial dilations (zero versus six patients), bronchial wall thickening (two versus eight patients) and an acinar pattern (one versus five patients). Mean thickness of the large airway wall to outer diameter (intermediary bronchus) ratio was 0.176 in COPD and 0.183 in AIRAO ( $>0.05)$.

CONCLUSIONS: Asthma may lead to physiological features similar to COPD but may be distinguished by demonstrating a preserved DLCO and a higher ratio of airway to parenchymal abnormalities on HRCT scan.

Key Words: Asthma with incomplete reversibility of airflow obstruction, Chronic obstructive pulmonary disease, Exercise tolerance, High resolution chest tomography, Pulmonary function tests

Pour le résumé, voir page 271

Correspondence and reprints: Dr Louis-Philippe Boulet, Hôpital Laval, 2725 Chemin Sainte-Foy, Sainte-Foy, Québec G1V 4 G5. Telephone 418-656-4747, fax 418-656-4762, e-mail medlpb@hermes.ulaval.ca 


\section{Comparaison entre l'asthme avec réversibilité incomplète de l'obstruction respiratoire et la MPOC sur le plan de leurs caractéristiques cli- niques, physiologiques et radiologiques}

OBJECTIFS : Comparer les caractéristiques cliniques, les résultats aux tests de fonction respiratoire et à la tomodensitométrie thoracique de haute résolution (TDM-HR) de patients asthmatiques présentant une réversibilité incomplète de leur obstruction respiratoire (ARIOR) à ceux de patients atteints de maladie pulmonaire obstructive chronique (MPOC) provoquée par le tabagisme .

MÉTHODES : On a étudié treize patients atteints de MPOC (six hommes et sept femmes, âgés en moyenne de 59,1 ans et fumant en moyenne 50,5 paquets de cigarettes par année) et 14 patients souffrant d'ARIOR (six hommes et huit femmes, âgés en moyenne de 52,0 ans) malgré un traitement optimal et en l'absence d'antécédents significatifs de tabagisme (moyenne 1,5 paquet par année), d'exposition ambiante ou d'autres maladies respiratoires quelles qu'elles soient. On a administré aux patients des questionnaires sur leur fonction respiratoire, des tests de fonction pulmonaire, des tests d'intradermoréaction et des TDM-HR pour déceler de possibles anomalies du parenchyme ou des bronches. Huit patients de chaque groupe ont également subi des épreuves d'effort. Tous les patients étaient stabilisés au moment de l'étude.

RÉSULTATS : Comme prévu, l'atopie s'est révélée plus prévalente chez les patients présentant un ARIOR $(n=13)$ que chez les patients atteints de MPOC $(n=1)$. Le volume expiratoire forcé en une seconde (VEMS) et le volume forcé (pourcentage de la valeur prévue) ont été respectivement de $39 \%$ et de $61 \%$ chez les patients atteints de MPOC et de $49 \%$ et $71 \%$ chez les patients souffrant d'ARIOR; le VEMS s'est amélioré de $18 \%$ et de $22 \%$ chez les patients atteints de MPOC et d'ARIOR, respectivement, après l'administration de salbutamol. La capacité fonctionnelle résiduelle a été plus grande chez les patients atteints de MPOC que chez les patients souffrant d'ARIOR (178\%, contre $144 \%$ de la valeur prévue), alors que la capacité de diffusion pulmonaire pour le monoxyde de carbone $\left(\mathrm{DLCO}_{2}\right)$ a été plus basse chez les patients atteints de MPOC que chez les patients souffrant d'ARIOR (62\%, contre $89 \%$ de la valeur prévue). La tolérance à l'effort a été semblable dans les deux groupes, tout comme les changements de la $\mathrm{PaO}_{2}$. Des anomalies associées à l'emphysème ont été notées chez les patients atteints de MPOC $(n=10)$ et chez les patients souffrant d'ARIOR $(n=13)$ qui présentaient une TDM-HR évaluable (10 patients, contre deux, quoique très léger dans l'asthme), les dilatations bronchiques (zéro patient, contre six), l'épaississement de la paroi bronchique (deux patients, contre huit) et un mode de présentation acineux (un patient contre cinq). Le ratio entre l'épaisseur moyenne de la paroi des voies respiratoires épaissie et le diamètre extérieur (bronche moyenne) a été de 0,176 dans la MPOC et de 0,183 dans l'ARIOR $(\mathrm{P}>0,05)$.

CONCLUSIONS : L'asthme peut éventuellement s'accompagner de caractéristiques similaires à celles de la MPOC, mais on le distingue en confirmant une $\mathrm{DLCO}_{2}$ préservée et un ratio anomalies des voies respiratoires:anomalies du parenchyme plus élevé à la TDMHR.
$\mathrm{R}$ espiratory diseases that induce airway obstruction can be subdivided into two main categories: asthma and chronic obstructive pulmonary disease (COPD). The latter disease includes primarily chronic bronchitis and emphysema $(1,2)$. These conditions are the most frequent chronic respiratory ailments in North America and are responsible for considerable morbidity (3). In asthma, airflow obstruction is usually completely reversible, either spontaneously or following treatment (1). This feature helps to distinguish asthma from COPD, although both diseases may occur concomitantly. On the other hand, in COPD, airflow obstruction related to prolonged smoking is mostly fixed (4). Although expiratory flows normalize completely in most asthmatic patients with appropiate treatment, an irreversible component of airflow obstruction (AIRAO) may be observed in some patients, even after optimal therapy and without any evidence of other pulmonary disease or significant smoking history (5-7). This subtype of asthma has previously been demonstrated to be associated with atopy, a prolonged duration of asthma, airway wall thickening and intense bronchial subepithelial collagen deposition, suggesting irreversible airway damage in this condition $(8,9)$. In clinical practice, AIRAO and COPD are difficult to differentiate, and the two conditions are often confounded.

Both asthma and COPD are associated with a complex bronchial inflammatory process $(10,11)$. They share numerous pathological similarities, such as epithelial desquamation, goblet cell metaplasia, mucous gland hyperplasia and smooth muscle hypertrophy $(11,12)$. Although many comparisons have been made between asthma with reversible air- flow obstruction and COPD, little is known of the comparative features of AIRAO and COPD.

The aim of this study was to compare the clinical, physiological and radiological features of patients with COPD with those of AIRAO not attributable to smoking or a condition other than asthma in order to identify features that may help differentiate these two conditions.

\section{PATIENTS AND METHODS}

Patients: Twenty-seven patients participated in this study: 13 patients (six males and seven females), aged 50 to 67 years, with smoking-induced COPD, and 14 asthmatic patients (six males and eight females), aged 40 to 64 years, with AIRAO (Table 1). COPD and asthma were defined according to the criteria of the American Thoracic Society (ATS), and AIRAO was defined as an optimal forced expiratory volume in $1 \mathrm{~s}\left(\mathrm{FEV}_{1}\right) 75 \%$ of the predicted value or less despite inhaled and systemic corticosteroid treatment $(8,13)$. Criteria for the AIRAO group were the typical symptoms of asthma, a less than $15 \%$ increase in $\mathrm{FEV}_{1}$ either spontaneously or following treatment, no significant history of smoking (less than six pack-years) and no environmental exposure or other condition, such as bronchiectasis, that could induce AIRAO.

Patients with contraindications to the proposed evaluation or with previous or current history of significant systemic or pulmonary disease other than asthma or COPD were excluded from the study, as were women of childbearing potential without adequate contraception and patients with unstable respiratory conditions because of a recent (less than one month) respiratory infection or allergen exposure. The 
TABLE 1

Subject characteristics

\begin{tabular}{lccc}
\hline & COPD & AIRAO & P \\
\hline Number of subjects & $13(6 \mathrm{M}, 7 \mathrm{~F})$ & $14(6 \mathrm{M}, 8 \mathrm{~F})$ & \\
Age (years) & 59.1 & 52.0 & 0.035 \\
& $(50$ to 67$)$ & $(40$ to 64$)$ & \\
Smoking history & 47.0 & 0 & $<0.0001$ \\
$\quad$ (pack-years) & $(24$ to 100$)$ & $(0$ to 6$)$ & \\
Atopy (number of & 1 & 13 & \\
$\quad$ subjects) & & & \\
Median baseline & 35.0 & 53.0 & 0.058 \\
$\quad$ FEV 1 (\% predicted) & $(19$ to 63$)$ & $(32$ to 63$)$ & \\
Median baseline & 51.0 & 53.5 & $>0.05$ \\
FEV $1 /$ FVC & $(10$ to 75$)$ & $(37$ to 63) & \\
(\% predicted) & & & \\
\hline
\end{tabular}

Data are expressed as means, with ranges in parentheses. AIRAO Asthmatic patients with a component of incomplete reversibility of airlow obstruction; COPD Chronic obstructive pulmonary disease; $\mathrm{F} \mathrm{Fe}$ male; FEV 1 Forced expiratory volume in $1 \mathrm{~s}$; FVC Forced vital capacity; M Male

study was approved by Laval University's Ethics Committee, and all patients signed informed consent forms.

Study design: Patients came to the laboratory on two to three different occasions. On a first visit, they completed a standardized questionnaire on the characteristics and duration of their disease, medication requirements, duration and severity of symptoms, disease-related global discomfort on a scale of 0 (no discomfort) to 5 (unbearable), smoking habits and environment. Patients were asked to evaluate their discomfort while under current medication.

Pre- and postbronchodilator expiratory flows, lung volumes, carbon monoxide diffusion (DLCO), airway resistance (Raw), specific conductance (SGaw), lung compliance (Cstat) and expiratory flows were measured. Allergy skinprick tests were also done at the first visit.

Patients were asked to measure their peak expiratory flows (PEF) with a mini-Wright peak flow meter four times daily, for a period of two weeks before the second visit. At that visit, high resolution chest tomography (HRCT) was done to measure bronchial wall thickness at the level of the right intermediary bronchus and to evaluate potential parenchymal or bronchial abnormalities.

Sixteen patients (eight COPD and eight AIRAO) agreed to a third visit, which allowed measurement of their exercise capacity and related parameters.

Procedures -Pulmonary function tests: Three reproducible measurements of $\mathrm{FEV}_{1}$ and forced vital capacity (FVC) were obtained before and after inhalation of $200 \mu \mathrm{g}$ salbutamol with a dry-seal spirometer, fulfilling ATS standards, by using predicted values reported by the ATS (14) and Knudson et al (15). Pulmonary volumes, Raw, SGaw and Cstat were measured by whole body plethysmography according to the method outlined by Dubois et al (16) or Dawson (17). DLCO was measured by single-breath method in all except four COPD patients in whom the steady-state method had to be used (18).

PEFs: All patients recorded on a diary card the best of three reproducible PEF measures taken with a mini-Wright peak flow meter, in the morning, at noon, before dinner and in the evening, for a two-week period.

Allergy skin tests: Skin-prick tests were performed with a battery of 26 common inhalants. Atopic status was defined as the presence of at least one positive reaction (wheal diameter more than $2 \mathrm{~mm}$ ) 10 mins after testing.

HRCT: HRCT was performed with a Toshiba (Kawasaki, Japan) fourth-generation TCT $900 \mathrm{~S}$ with high resolution technique according to Mayo et al (19). Nonangulated $2 \mathrm{~mm}$ thick slices at $10 \mathrm{~mm}$ increments were obtained through the lungs without contrast injection, and sections were obtained with reconstruction centred on the right intermediary bronchus. The matrix size was $512 \times 512$ at a pixel size of $0.6 \mathrm{~mm}$, with a scanning time of $1 \mathrm{~s}$. Blind measurements were recorded at total lung capacity (TLC) in the supine position. Images were recorded at a window width of $1600 \mathrm{HU}$ and a window level of $-600 \mathrm{HU}$. Scans were interpreted without knowledge of their origin (COPD or AIRAO) and after agreement by two radiologists. Criteria for HRCT features were established according to previously reported criteria (20). Descriptions of bronchiectasis and mucoid impactions were based on the criteria established for high resolution chest tomography by Naidich et al (21) and Grenier et al (22). Emphysematous changes were characterized according to the criteria of Foster et al (23), and atelectasis and acinar pattern to those of Naidich et al (24). Bronchial wall thickening was defined according to the criteria described by Naidich et al (24) and Zerhouni (25). Peripheral airway wall thickening was qualitatively assessed from the different HRCT sections following agreement between two observers and was specifically measured at the level of the large airways by the following method. For comparison between groups, the ratio of airway wall thickness to its diameter (T:D) was obtained to characterize large bronchi. Main right intermediary bronchus diameter and wall thickness were calculated as follows: internal diameter was the smallest internal diameter measured; wall thickness was measured in the same axis as that of adjacent internal bronchial diameter; and the total bronchial diameter was the sum of the internal diameter and twice the wall thickness. Airway narrowing was defined as an airway with a diameter less than one-half the diameter of an adjacent vessel. All measurements were taken with electronic calipers.

Exercise tests: An arterial canula was placed in a radial artery. Subjects were then seated on an electrically braked ergocycle and connected to the exercise circuit through a mouthpiece. Five-breath averages of minute ventilation $\left(V_{\mathrm{E}}\right)$ oxygen uptake $\left(\mathrm{VO}_{2}\right)$ and carbon dioxide excretion $\left(\mathrm{V}_{\mathrm{CO}}\right)$ were measured with the exercise circuit equipped with a pneumotachograph, oxygen and carbon dioxide analyzers, and a mixing chamber (Quinton Qplex, A-H Robins Company, Washington). After 5 mins at rest, a progressive stepwise exercise test was performed up to the individual's maximum capacity (26). Each exercise step lasted $1 \mathrm{~min}$, and increments of 10 or $15 \mathrm{~W}$ were used. During exercise, arterial blood samples were drawn at rest and at maximum exercise capacity to determine lactate concentration and blood gases. 
Statistical Analysis: Patient's dead space volume ( $\left.V_{\mathrm{D}}\right)$ to $V_{\mathrm{E}}$ ratio was calculated as follows.

$$
V_{D}: V_{E}=\frac{V_{E}-V_{A}-V_{D_{\text {app }}}}{V_{E}-V_{D_{\text {app }}}}
$$

where $V_{\mathrm{E}}$ is the minute ventilation in litres; $V_{\mathrm{A}}$ is the alveolar ventilation:

$$
V_{A}=\frac{\dot{V} \mathrm{CO}_{2} \times 0.863}{\mathrm{PaCO}_{2}}
$$

$V_{\text {app }}$ is the dead space of the apparatus, $\dot{V} \mathrm{CO}_{2}$ is expressed in $\mathrm{mL} / \mathrm{min}, \mathrm{PaCO}_{2}$ is the arterial carbon dioxide pressure in $\mathrm{mmHg}$ and $V_{\text {Dapp }}$ is $0.085 \mathrm{~L}$ multiplied by the respiratory rate.

Results are expressed as medians and ranges; median and range values were preferred because they reflect more accurately the tendencies of the two groups (one subject with AIRAO had outstanding performances on exercise test, modifying considerably the means for several measurements). Because variance and normality assumption were not met, unpaired $t$ tests on transformed values in their ranks were used to compare duration of asthma, expiratory flows, bronchodilator response, lung volumes, DLCO, Cstat, Raw, sGaw, mean diurnal variation of PEF, and global discomfort in patients with COPD and AIRAO. Radiological findings were compared using Fisher's exact tests. Reported P values are two-sided. $\mathrm{P}<0.05$ was considered statistically significant. Data were analyzed using SAS (SAS Institute Inc, North Carolina).

\section{RESULTS}

Patients' clinical features: The time of diagnosis ranged from one to 37 years (median five years) in COPD patients, while asthma duration was one to 49 years (median 35 years) in the AIRAO patients $(\mathrm{P}=0.0002)$. Atopy was present in only one COPD patient (allergic to housedust, domestic animals and pollens) and in all AIRAO patients except for one (allergic to housedust or housedust mite $[\mathrm{n}=10]$ and/or domestic animals [ $n=7]$ and/or pollens [ $n=8]$ ). COPD patients had a significant smoking history (eight smokers and five ex-smokers; 24 to 100 pack-years [median 47.0 pack-years]) compared with those with AIRAO (10 nonsmokers and four ex-smokers [three, six, six and six pack-years, respectively; median 0 pack-years).

All patients used inhaled beta2-agonists, while inhaled beclomethasone was taken by seven COPD patients and all AIRAO patients (mean daily doses 580 and $1760 \mu \mathrm{g}$, respectively). Three COPD and eight AIRAO patients took theophylline, and seven COPD patients took ipratropium. Two COPD and three AIRAO patients used prednisone regularly, at daily doses of $20 \mathrm{mg}$ and $50 \mathrm{mg}$ for the two COPD patients, and $5 \mathrm{mg}, 15 \mathrm{mg}$ and $20 \mathrm{mg}$ for the three AIRAO patients.

The rating of disease-related global discomfort was similar in COPD and AIRAO patients (median 3, range 2 to 4 for COPD patients and median 3 , range 0 to 4 for AIRAO patients; $\mathrm{P}>0.05$ ).

Pulmonary function tests: Median and range of baseline
TABLE 2

Radiological parameters (high resolution computed chest tomography)

\begin{tabular}{lccc}
\hline & $\begin{array}{r}\text { COPD } \\
(\mathbf{n = 1 0 )}\end{array}$ & $\begin{array}{c}\text { AIRAO } \\
(\mathbf{n}=12)\end{array}$ & $\mathbf{P}$ \\
\hline Bronchial dilations & 0 & $6^{*}$ & 0.011 \\
Bronchial wall thickening & 2 & 8 & 0.023 \\
Bronchial wall narrowing & 0 & 4 & 0.087 \\
Emphysematous change & 10 & 2 (discrete) & 0.0007 \\
Acinar pattern & 1 & 5 & 0.141 \\
\hline
\end{tabular}

*Mostly central. AIRAO Asthmatic patients with a component of incomplete reversibility of airflow obstruction; COPD Chronic obstructive pulmonary disease

$\mathrm{FEV}_{1}$ and $\mathrm{FVC}$ (in percentage of predicted value) were $35 \%$ (19\% to 63\%) and 59\% (34\% to 95\%), respectively, in COPD patients and $53 \%$ (42\% to $63 \%, \mathrm{P}=0.058)$ and $71 \%$ (49\% to 98\%, $\mathrm{P}=0.085$ ), respectively, in AIRAO patients (Figure 1). Postbronchodilator $\mathrm{FEV}_{1}$ and $\mathrm{FVC}$ were improved by $22.7 \%$ $(-13 \%$ to $52 \%)$ and $15.6 \%$ ( $-20 \%$ to $48 \%)$, respectively, in COPD patients and by $18.5 \%$ (10\% to $50 \%)$ and $14 \%$ (1\% to $41 \%$ ), respectively, in AIRAO patients (both $\mathrm{P}<0.05$ ). The $\mathrm{FEV}_{1}$ to $\mathrm{FVC}$ ratio was similar in COPD $(0.51,10 \%$ to $75 \%$ of predicted) and AIRAO patients $(0.54,37 \%$ to $63 \%$ of predicted).

TLC was slightly greater in COPD than in AIRAO patients (Figure 2). Residual volume (RV) $(\mathrm{P}=0.015)$ and functional residual capacity $(\mathrm{FRC})(\mathrm{P}=0.042)$ were significantly increased in COPD compared with AIRAO patients. DLCO was significantly lower in COPD patients, with a median baseline value of $58 \%$ of the predicted value compared with 90.5\% of the predicted value in AIRAO patients $(\mathrm{P}=0.0024)$; 10 COPD and four AIRAO patients had a baseline DLCO of less than $80 \%$ of predicted values. Median baseline Raw, sGaw and Cstat were 4.1 (range 2.5 to 5.9 ) $\mathrm{cm} \mathrm{H}_{2} \mathrm{O} / \mathrm{L} / \mathrm{s}, 0.05$ (range 0.02 to 0.20 ) $\mathrm{L} / \mathrm{s} / \mathrm{cm} \mathrm{H}_{2} \mathrm{O}, 0.151$ (range 0.079 to $0.246) \mathrm{L} / \mathrm{cm} \mathrm{H}_{2} \mathrm{O}$, respectively, in the COPD group and 4.0 (range 3.0 to 6.9 ) $\mathrm{cm} \mathrm{H}_{2} \mathrm{O} / \mathrm{L} / \mathrm{s}, 0.050$ (range 0.04 to 0.08 ) $\mathrm{L} / \mathrm{s} / \mathrm{cm} \mathrm{H}_{2} \mathrm{O}, 0.169$ (range 0.078 to 0.350 ) $\mathrm{L} / \mathrm{cm} \mathrm{H}_{2} \mathrm{O}$, respectively, in the AIRAO group (all $\mathrm{P}>0.05$ ).

PEF: Median daily changes in PEF were similar in patients with COPD and AIRAO, with respective changes of $22.6 \%$ and $13.0 \%$ ( $P>0.05$; Figure 3 ). Maximum daily change in PEF observed over the two-week period was $35.0 \%$ in COPD and $21.9 \%$ in AIRAO patients $(\mathrm{P}=0.05)$.

HRCT findings: Twelve patients with COPD and 13 with AIRAO agreed to have an HRCT; results were evaluable in 10 COPD and 12 AIRAO patients (T:D ratio only was measured in the other AIRAO patient; computed tomography scans were not evaluable because of the presence of linear artefacts [Table 2]). Bronchial dilations were found exclusively in AIRAO patients $(n=6, P=0.011)$. Bronchial wall thickening was found in both groups but was more frequent in $\operatorname{AIRAO}(\mathrm{n}=8)$ than in COPD patients $(\mathrm{n}=2, \mathrm{P}=0.023)$; bronchial wall narrowing was observed only in four AIRAO patients $(\mathrm{P}>0.05)$. Emphysematous changes occurred in all COPD patients, being discrete in two patients, moderate in five and important in two, while in patients with AIRAO, 


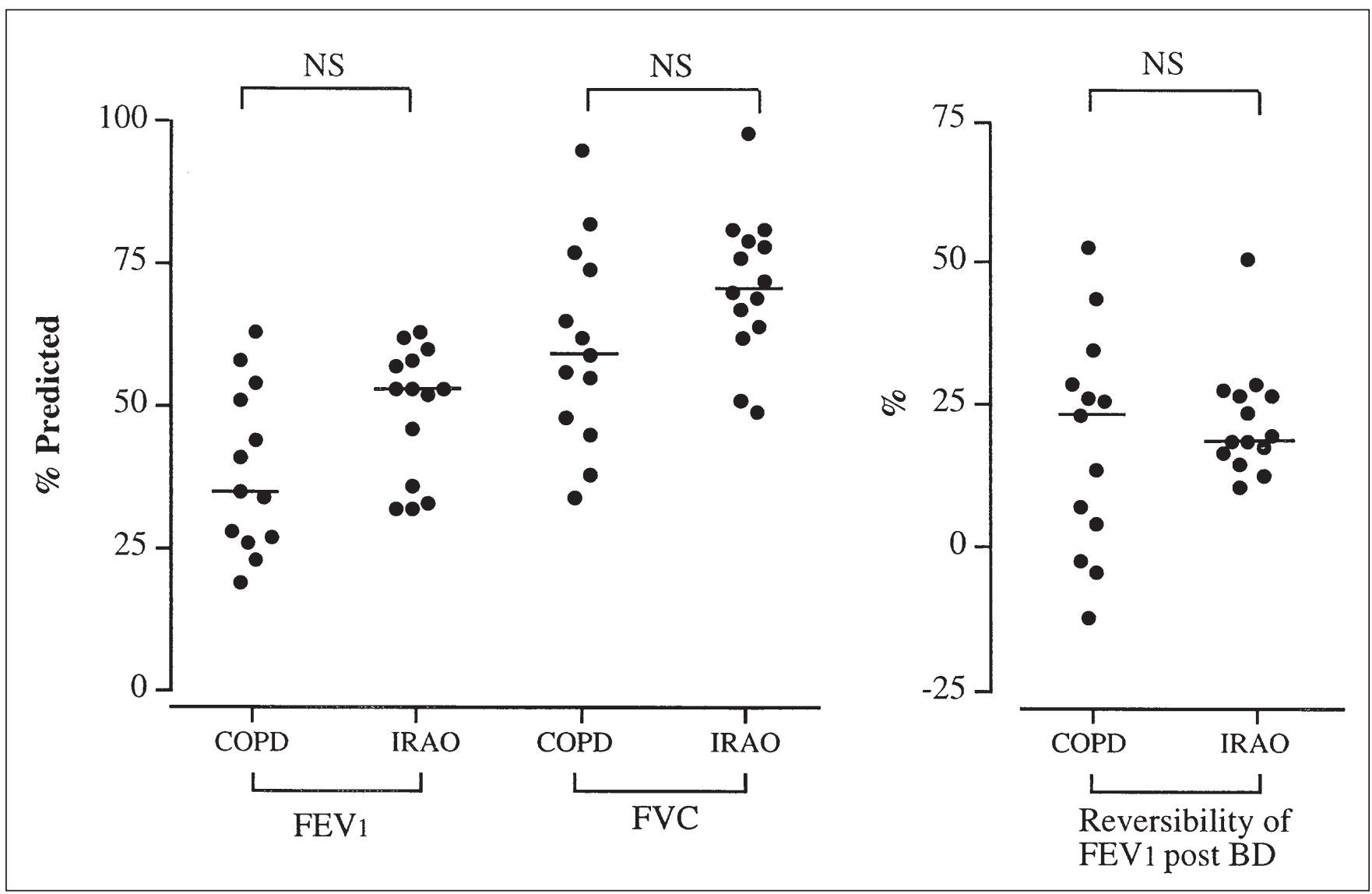

Figure 1) Individual data and medians of expiratory flows in the two groups studied at baseline evaluation and after administration of $200 \mu \mathrm{g}$ of inhaled salbutamol. BD Bronchodilator; COPD Chronic obstructive pulmonary disease; FEVI Forced expiratory volume in 1 s; FVC Forced vital capacity; IRAO Incomplete reversibility of airflow obstruction; NS Not significant

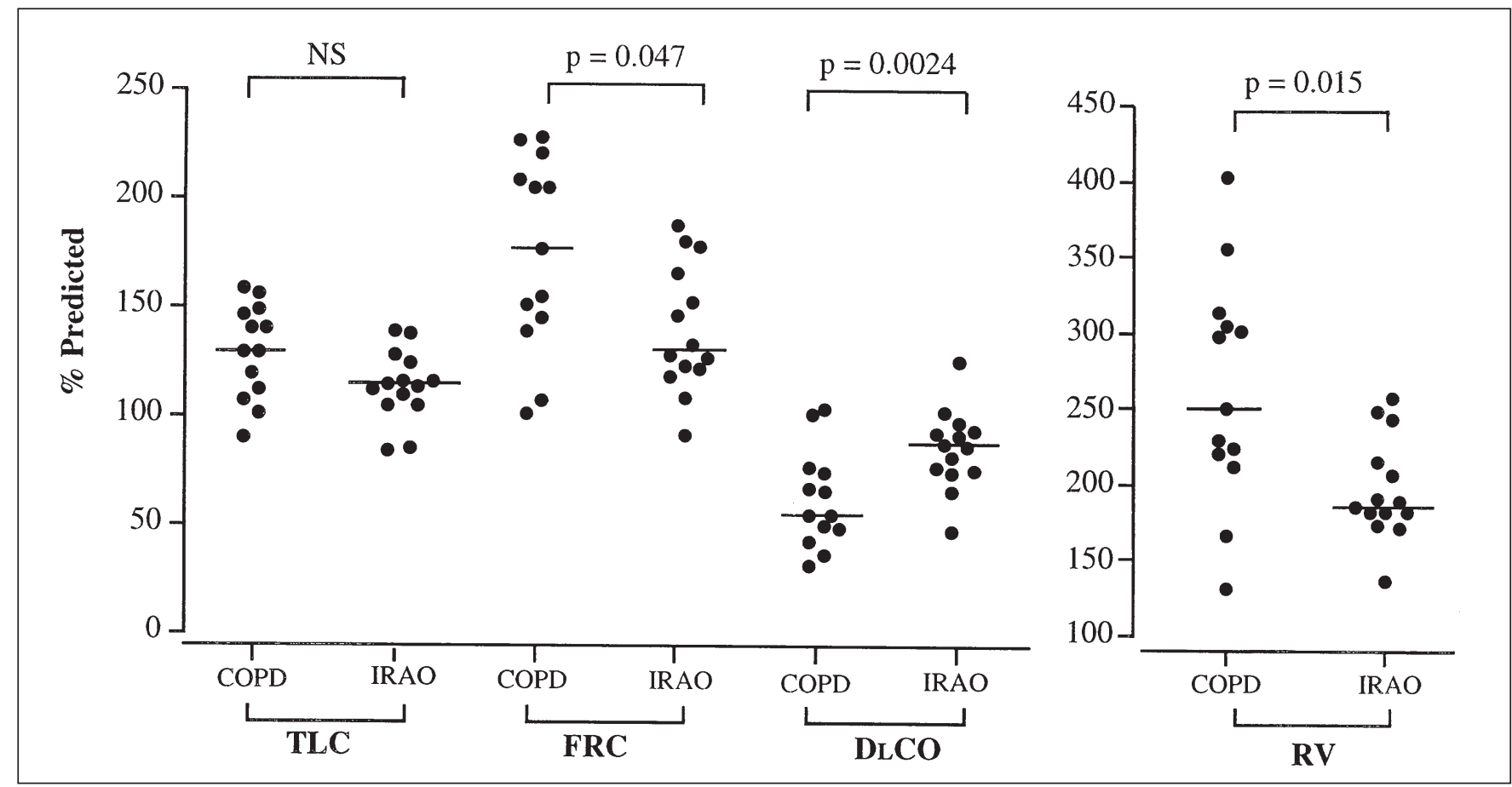

Figure 2) Individual data and medians for total lung capacity (TLC), functional residual capacity (FRC), carbon monoxide diffusion (DLCO) and residual volume $(R V)$. COPD Chronic obstructive pulmonary disease; IRAO Incomplete reversibility of airflow obstruction; NS Not significant 
only two showed discrete manifestations of emphysema $(\mathrm{P}=0.0007)$. Only five AIRAO patients presented focal areas of acinar pattern; this alteration was present and focal in one COPD patient $(\mathrm{P}>0.05)$. T:D was similar in COPD $(0.18$; range 0.11 to 0.29$)$ and $\operatorname{AIRAO}(0.18$, range 0.13 to 0.21 , $\mathrm{P}>0.05)$ patients. No significant correlations were found between T:D and either DLCO or $V \mathrm{O}_{2 \max }$ or $V_{\text {Emax }}$ (in percentage of predicted values).

Exercise tests: Eight COPD (four males and four females; mean age 59.4 \pm 2.2 years) and eight AIRAO patients (four males and four females; mean age $49.9 \pm 3.2$ years, $\mathrm{P}=0.04$ ) had an exercise test. Baseline and end of exercise parameters are given in Table 3. Median peak-minute ventilations were 47.8 and $57.4 \mathrm{~L} / \mathrm{min}$ (102.7\% and $89.5 \%$ predicted) in COPD and AIRAO patients, respectively, representing $117.5 \%$ and $91.5 \%$ of maximum voluntary ventilation (MVV), where $\mathrm{MMV}=\mathrm{FEV}_{1} \times 35$ (27).

Maximum heart rate was slightly greater in AIRAO patients, but this difference did not reach statistical significance when expressed as percentage predicted. Although the median arterial oxygen saturation was lower at rest in COPD patients, this value was similar for both groups at end of exercise. In contrast, exercise hypercapnia was frequently observed in COPD patients with a median end of exercise $\mathrm{PaCO}_{2}$ value of $45.0 \mathrm{mmHg}$, which was significantly greater than the $\mathrm{PaCO}_{2}$ of $38.5 \mathrm{mmHg}$ found in AIRAO patients $(\mathrm{P}<0.05)$. The $\mathrm{V}_{\mathrm{D}}$ to $V_{\mathrm{E}}$ ratio was significantly greater in COPD than in AIRAO patients, both at rest and at the end of exercise: respective median ratios were 0.56 (range 0.381 to 0.67 ) and 0.44 (range 0.31 to 0.53 ) at rest $(\mathrm{P}=0.011)$ and 0.47 (range 0.31 to 0.59$)$ and 0.35 (0.22 to 0.50$)$ at the end of exercise $(\mathrm{P}=0.049)$.

\section{DISCUSSION}

Little attention has been paid to the potential clinical and functional consequences of an irreversible component of airflow obstruction associated with long standing asthma. This condition is also difficult to differentiate from COPD and is confusing for the clinician. Therefore, a need exists to characterize the clinical, functional and radiological status of these patients and to compare these features with those of patients with smoking-induced COPD in order to determine whether different types of inflammatory damage to the airways have the same consequences $(11,12)$.

We found that for a similar degree of airflow obstruction, AIRAO differs from COPD in showing no reduction in DLCO, less hyperinflation and fewer parenchymal abnormalities. Exercise tolerance was similar in the two groups. Large airway wall thickness, as reported by the T:D of the intermediary bronchus, was similar in the two groups, although many patients with AIRAO showed evidence of small and medium airway wall thickening.

In the present study, we did not compare AIRAO with a control group of normal or asthmatic subjects with reversible airflow obstruction because this had been done previously (9). Studies that compared histopathological airway changes in asthma and COPD have previously shown that apart from

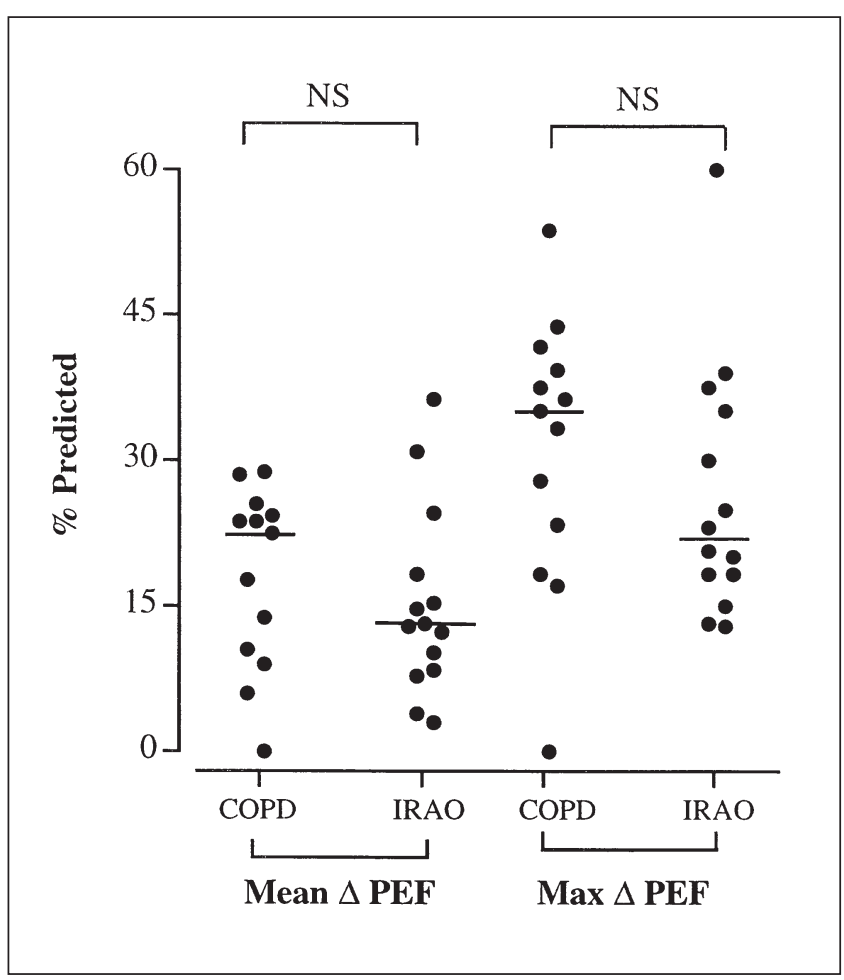

Figure 3) Mean and maximal change in postbronchodilator peak expiratory flow $(P E F)$. Bar represents medians. COPD Chronic obstructive pulmonary disease; IRAO Incomplete reversibility of airflow obstruction; NS Not significant

the associated air-space destruction, the main difference between the two conditions was the increased subepithelial collagen deposition and the increased number of lymphocytes, mast cells and eosinophils in asthma $(11,28)$.

The physiopathology of AIRAO without associated smoking-related COPD is still uncertain (29), but some physiological and radiological features may help to distinguish the two conditions. In COPD, in contrast to AIRAO, DLCO capacity is reduced, possibly in relation to the frequent and severe parenchymal damage observed (30). On the other hand, AIRAO is characterized by bronchial defects, including airway wall thickening, mostly at the level of small and intermediary bronchi. As indicated by similar T:D ratios, the large airways' wall thicknesses were similar in the two groups. This can be explained by the type of inflammatory insult and the respective physiopathology of these diseases, involving the protease-inhibitor system and a neutrophilic inflammation in COPD, and an eosinophilic bronchitis with a more intense airway repair process (eg, collagen deposition) in asthma $(12,28,31)$.

Despite significant airflow obstruction, exercise capacity was relatively preserved in both groups. This illustrates the weak relationship between indexes of airflow obstruction and exercise capacity (32). However, as in COPD, our data show that in asthma with fixed airflow obstruction, marked reduction in exercise tolerance may occur, although it is quite variable from one subject to another. In addition, the response to exercise was abnormal in both groups. As indicated 
TABLE 3

Median (range) values for exercise tests

\begin{tabular}{|c|c|c|c|}
\hline & COPD $(n=8)$ & AIRAO $(n=8)$ & $\mathbf{P}$ \\
\hline $\mathrm{FEV}_{1}(\%$ predicted $)$ & 42.5 (19 to 63$)$ & 52.5 (33 to 63 ) & $>0.05$ \\
\hline $\mathrm{VO}_{2 \max }(\mathrm{L} / \mathrm{min})$ & $1.30(0.97$ to 2.36$)$ & 1.40 (0.76 to 3.48$)$ & $>0.05$ \\
\hline $\begin{array}{l}V O_{2 \max } \\
\text { (\% predicted) }\end{array}$ & 77 (58 to 106$)$ & 81 (51 to 142$)$ & $>0.05$ \\
\hline Maximum power $(\mathrm{W})$ & 75 (60 to 150$)$ & 85 (50 to 260$)$ & $>0.05$ \\
\hline$\dot{V}_{E \max }(\mathrm{L} / \mathrm{min})$ & 47.8 (34.3 to 85.7$)$ & $57.4(28.8$ to 115.5$)$ & $>0.05$ \\
\hline$\dot{V}_{E \max }(\%$ predicted $)$ & 102.7 (78 to 120$)$ & 89.5 (67 to 178$)$ & $>0.05$ \\
\hline$\dot{V}_{E \max } / M V V(\%)$ & 117.5 (80 to 144$)$ & 91.5 (65 to 140$)$ & $>0.05$ \\
\hline Maximum heart rate (beat/min) & $143.5(120$ to 165$)$ & $164.5(119$ to 176$)$ & 0.0008 \\
\hline Maximum heart rate (\% predicted) & 84.0 (72 to 95$)$ & 94.5 (70 to 97$)$ & 0.058 \\
\hline Lactate at rest $(\mathrm{mmol} / \mathrm{L})$ & $0.66(0.44$ to 0.93$)$ & 0.75 (0.44 to 1.23$)$ & $>0.05$ \\
\hline Lactate at end of exercise $(\mathrm{mmol} / \mathrm{L})$ & $4.99(1.02$ to 5.04$)$ & 5.51 (3.85 to 14.38$)$ & $>0.05$ \\
\hline $\mathrm{SaO}_{2}$ at rest $(\%)$ & 0.96 (0.93 to 0.98$)$ & $0.98(0.97$ to 0.99$)$ & 0.008 \\
\hline $\mathrm{SaO}_{2}$ at end of exercise (\%) & 0.95 (0.89 to 0.98$)$ & 0.97 (0.90 to 0.98$)$ & $>0.05$ \\
\hline $\mathrm{PaCO}_{2}$ at rest $(\mathrm{mmHg})$ & 43.0 (31 to 49$)$ & 39.0 (29 to 43 ) & $>0.05$ \\
\hline $\mathrm{PaCO}_{2}$ at end of exercise $(\mathrm{mmHg})$ & 45.0 (39 to 58$)$ & 38.5 (33 to 52 ) & 0.049 \\
\hline$V_{D}: \dot{V}_{E}$ at rest $(\%)$ & 55.8 (38.2 to 66.7 ) & 43.8 (30.8 to 52.6$)$ & 0.011 \\
\hline$V_{\mathrm{D}}: \dot{V}_{E}$ at end of exercise (\%) & 47.0 (30.7 to 59.1$)$ & 34.9 (22.2 to 49.8$)$ & 0.049 \\
\hline
\end{tabular}

FEV 1 Forced expiratory volume in $1 \mathrm{~s} ; \mathrm{MVV}$ Maximum voluntary ventilation; $\mathrm{PaCO}_{2}$ Arterial carbon dioxide pressure; $\mathrm{SaO} \mathrm{A}_{2}$ Arterial oxygen saturation; $\mathrm{VO}_{2 \max }$ Maximum oxygen uptake; $\mathrm{V}_{D}: \dot{V}_{E}$ Ratio of patient's dead space to minute ventilation; $\dot{V}_{E}$ max Maximum minute ventilation

by the $V_{\text {Emax }}$ percentage of predicted, the ventilatory response was abnormal with an excessive increase in $V_{\mathrm{E}}$ for the exercise level. Because of the disproportionate increase in $V_{\mathrm{E}}$ and the reduction in MVV, the breathing reserve

$$
1-\frac{V_{E \max }}{M V V}
$$

was markedly reduced, indicating the presence of ventilatory limitation in both groups (33). Despite a slightly lower exercise capacity, the end-exercise $P_{a C O}$ was higher in COPD patients than in AIRAO patients. This probably partly reflects the higher resting $\mathrm{PaCO} 2$ of the COPD patients (although the difference for $\mathrm{PaCO} 2$ at rest between the two groups did not reach statistical significance). This was probably also partly related to a greater $V_{D}$ to total volume ratio in these patients. In addition, in COPD patients who were breathing at higher lung volume, it is conceivable that the respiratory muscles were more mechanically disadvantaged (34). This negative effect of lung volume on respiratory muscle function, which might have been amplified during exercise (35), may also have contributed to the end of exercise increase in $\mathrm{PaCO}_{2}$ (36).

Radiological techniques have been used to investigate airway wall and parenchymal abnormalities in obstructive diseases. Previous studies of airway structural changes using HRCT have shown that patients with more severe asthma tended to have more irreversible abnormalities such as bronchiectasis, bronchial wall thickening and emphysema $(37,38,39)$. Paganin et al $(38)$ also showed that patients with nonallergic asthma seem to have more extensive remodelling of airways than allergic patients. Finally, observations of Okazawa et al (39) suggest that in asthma, small and medium calibre airways show an increased wall thickness that may contribute to the physiological abnormalities observed in these patients (39). With regard to COPD, previous publications have described different parenchymal alterations, but to our knowledge, these studies have not compared COPD with asthma, particularly with regard to airway and parenchymal changes $(23,40)$.

Because there is a relationship between the severity of asthma and the HRCT abnormalities, and because patients with AIRAO included in the present investigation had moderate to severe disease, our results should not be extended to the entire asthmatic population. Nevertheless, our observations should help to better characterize this subpopulation of asthmatic subjects, indicating that asthma may sometimes lead to significant functional and airway structural changes of similar magnitude to those found in COPD. This suggests that airway inflammation, whether intense, of long duration or insufficiently treated, may be responsible for irreversible changes that lead to significant disability. Further studies of the long term outcomes of these asthmatic subjects would help to determine whether the rate of decline of pulmonary function is similar to that found in COPD patients who stopped smoking, as well as examine the influence of different treatment modalities on these outcomes (42).

In conclusion, although our two study groups had different types of anatomical and physiological impairment, the functional consequences of these two types of obstructive diseases were broadly similar.

ACKNOWLEDGEMENTS: We thank Lori Schubert for reviewing the manuscript. 


\section{REFERENCES}

1. McFadden ER Jr, Gilbert IA. Asthma. N Engl J Med 1992;327:1928-37.

2. Burrows B. Epidemiologic evidence for different types of chronic airflow obstruction. Am Rev Respir Dis 1991;143:1452-4.

3. Sherrill DL, Lebowitz MD, Burrows B. Epidemiology of chronic obstructive pulmonary disease. Clin Chest Med 1990;11:375-87.

4. Burrows B. Airway obstructive diseases: pathogenetic mechanisms and natural histories of the disorders. Med Clin North Am 1990;74:547-59.

5. Brown PJ, Greville HW, Finucane KE. Asthma and irreversible airflow obstruction. Thorax 1984;39:131-6.

6. Nelson HS. The natural history of asthma. Ann Allergy 1991;66:196-203.

7. Finucane KE, Greville HW, Brown PJE. Irreversible airflow obstruction: evolution in asthma. Med J Aust 1985;142:602-4.

8. Boulet LP, Bélanger M, Carrier G. Airway responsiveness and bronchial-wall thickness in asthma with or without fixed airflow obstruction. Am J Respir Crit Care Med 1995;152:865-71.

9. Hudon C, Turcotte H, Carrier G, et al. Characteristics of non-smoking asthmatic subjects with a component of fixed airway obstruction. Am Rev Respir Dis 1994;149:A188. (Abst)

10. Kay AB. Asthma and inflammation. J Allergy Clin Immunol 1991;87:893-910.

11. Ollerenshaw S, Woolcock AJ. Characteristics of the inflammation in biopsies from large airways of subjects with asthma and subjects with chronic airflow limitation. Am Rev Respir Dis 1992;145:922-7.

12. Djukanovic R, Roche WR, Wilson JW, et al. Mucosal inflammation in asthma. Am Rev Respir Dis 1990;142:434-57.

13. Standards for the diagnosis and care of patients with chronic obstructive pulmonary disease (COPD) and asthma. American Thoracic Society Board of Directors, November 1986. Am Rev Respir Dis 1987;136:225-44.

14. ATS statement - Snowbird workshop on standardization of spirometry. Am Rev Respir Dis 1979;119:831-8.

15. Knudson RJ, Lebowitz MD, Holberg CJ, Burrows B. Changes in the normal expiratory flow volume curve with growth and aging. Am Rev Respir Dis 1983;127:725-34.

16. Dubois AB, Botelho SY, Bedell GN, et al. A rapid plethysmographic method for measuring thoracic gas volume; a comparison with nitrogen washout method for measuring functional residual capacity. J Clin Invest 1956;35:322-6.

17. Dawson A. Elastic recoil and compliance. In: Clausen JL, ed. Pulmonary Function Testing: Guidelines and Controversies. Toronto: Academic Press, 1982:193-204.

18. Ayers LN. Carbon monoxide diffusing capacity. In: Wilson AF, ed. Pulmonary Function Testing: Indications and Interpretations. Orlando: Grune Straton, 1985:137-51.

19. Mayo JR, Webb WR, Gould R, et al. High resolution CT of the lungs: an optimal approach. Radiology 1987;163:507-10.

20. Hudon C, Turcotte H, Laviolette M, Carrier G, Boulet L-P. Characteristics of bronchial asthma with incomplete reversibility of airflow obstruction. Ann Allergy Asthma Immunol 1997;78:195-202.

21. Naidich DP, McCauley DI, Khouri NF, Stitik FP, Siegelman SS. Computed tomography of bronchiectasis. J Comput Assist Tomogr 1982;6:437-44.
22. Grenier P, Maurice F, Musset D, Menu Y, Nahum H. Bronchiectasis: assessment by thin-section CT. Radiology 1986;161:95-9.

23. Foster WL Jr, Pratt PC, Roggli VL, Godwin JD, Halvorsen RA Jr, Putman CE. Centrilobular emphysema: CT-pathologic correlation. Radiology 1986;159:27-32.

24. Naidich DP, Zerhouni EA, Siegelman SS. Computed Tomography of the Thorax. New York: Raven Press, 1984.

25. Zerhouni EA. Sémiologie tomodensitométrique pulmonaire. In: Grenier $\mathrm{P}$, ed. Imagerie Thoracique de l'adulte. Paris: Flammarion, 1988;197-204.

26. Jones NL, Campbell EJM. Clinical Exercise Testing, 2nd edn. Toronto: EW Saunders, 1982:83-111.

27. Clark TJ, Freedman S, Campbell EJ, Winn RR. The ventilatory capacity of patients with chronic airways obstruction. Clin Sci 1969;36:307-16

28. Thurlbeck WM. Pathology of chronic airflow obstruction. Chest 1990;97(2 Suppl):6S-10S

29. Burrows B, Bloom JW, Traver GA, Cline MG. The course and prognosis of different forms of chronic airway obstruction in a sample from the general population. N Engl J Med 1987;317:1309-14.

30. Gelf AF, Schein M, Kuei J, et al. Limited contribution of emphysema in advanced chronic obstructive pulmonary disease. Am Rev Respir Dis 1993; 147:1157-61.

31. Stockley RA. The role of proteinases in the pathogenesis of chronic bronchitis. Am J Respir Crit Care Med 1994;150:S109-13.

32. Jones NL, Killian KJ. Limitation of exercise in chronic airway obstruction. In: Cherniack NS, ed. Chronic Obstructive Pulmonary Disease. Philadelphia: WB Saunders, 1991:196-206.

33. Weisman IM, Zeballos RJ. An integrated approach to the interpretation of cardiopulmonary exercise testing. Clin Chest Med 1994;15:421-45.

34. Similowski T, Yan S, Gauthier AP, Macklem PT, Bellemare F. Contractile properties of the human diaphragm during chronic hyperinflation. N Engl J Med 1991;325:917-23.

35. Dodd DS, Brancatisano T, Engel LA. Chest wall mechanics during exercise in patients with severe chronic air-flow obstruction. Am Rev Respir Dis 1984;129:33-8.

36. Bégin $\mathrm{P}$, Grassino AE. Inspiratory muscle dysfunction and chronic hypercapnia in chronic obstructive pulmonary disease. Am Rev Respir Dis 1991;143:905-12.

37. Paganin F, Trussard V, Séneterre $P$, et al. Chest radiography and high resolution computed tomography of the lungs in asthma. Am Rev Respir Dis 1992;146:1084-7.

38. Paganin F, Séneterre P, Chanez P, et al. Computed tomography of the lungs in asthma: influence of disease severity and etiology. Am J Respir Crit Care Med 1996;153:110-4.

39. Okazawa M, Müller N, McNamara AE, Child S, Verburgt L, Pare PD. Human airway narrowing measured using high resolution computed tomography. Am J Respir Crit Care Med 1996;154:1557-62.

40. Miniati M, Filippi E, Falaschi F, et al. Radiologic evaluation of emphysema in patients with chronic obstructive pulmonary disease. Chest radiography versus high resolution computed tomography. Am J Respir Crit Care Med 1995;151:1359-67.

41. Dompeling E, van Schayck CP, van Grunsven PM, et al. Slowing the deterioration of asthma and chronic obstructive pulmonary disease observed during bronchodilator therapy by adding inhaled corticosteroids. A 4-year prospective study. Ann Intern Med 1993;118:770-8. 


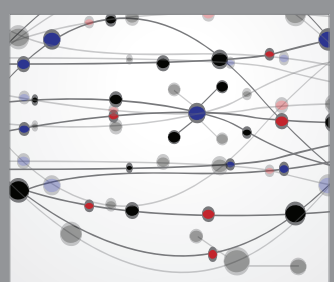

The Scientific World Journal
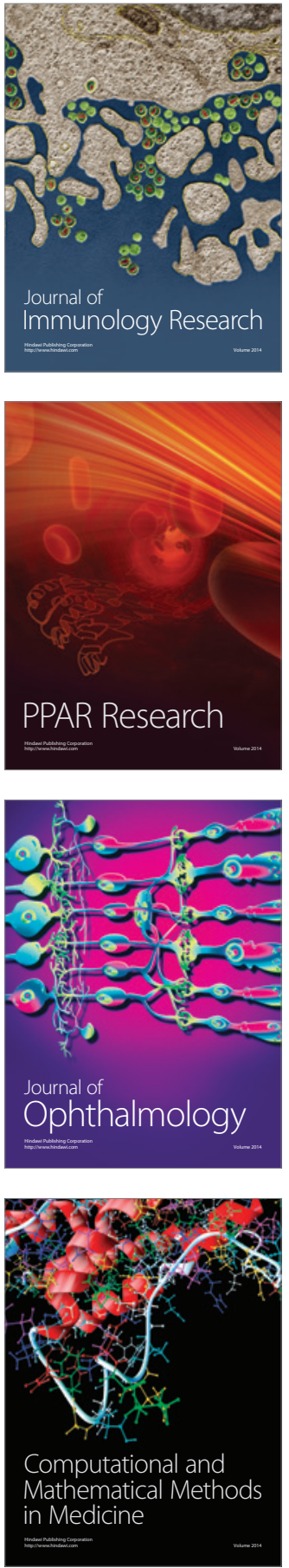

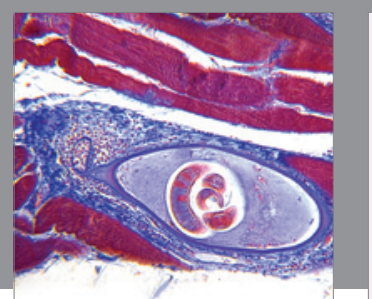

Gastroenterology Research and Practice

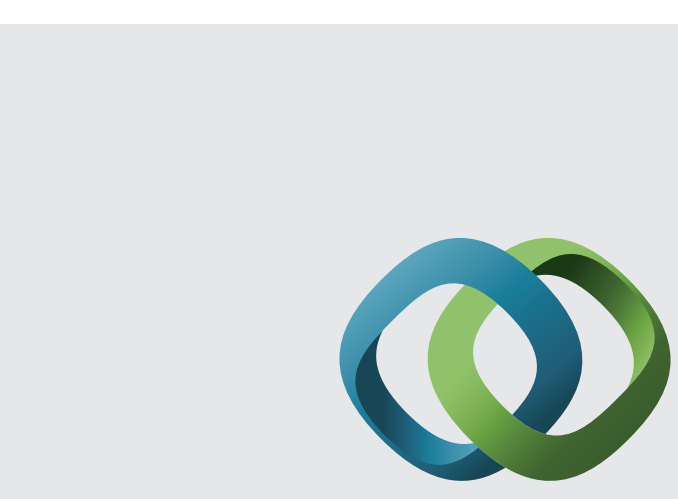

\section{Hindawi}

Submit your manuscripts at

http://www.hindawi.com
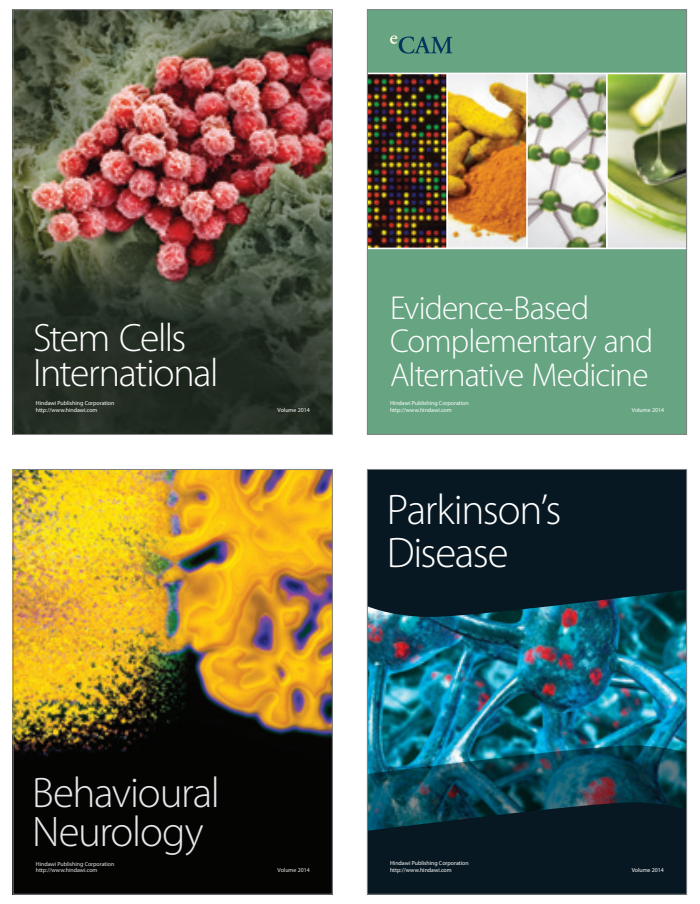
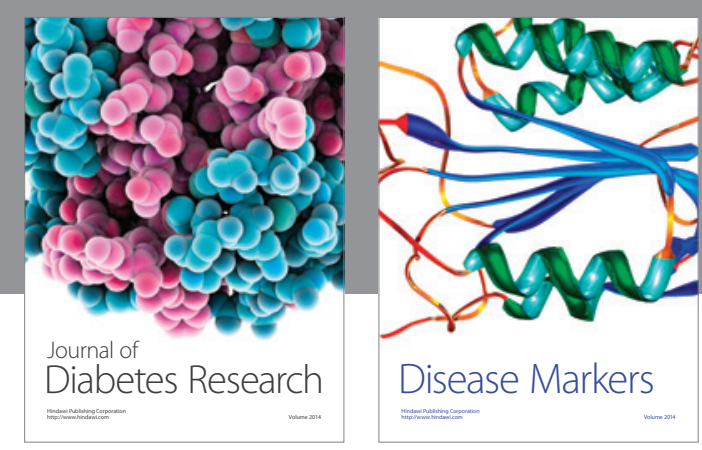

Disease Markers
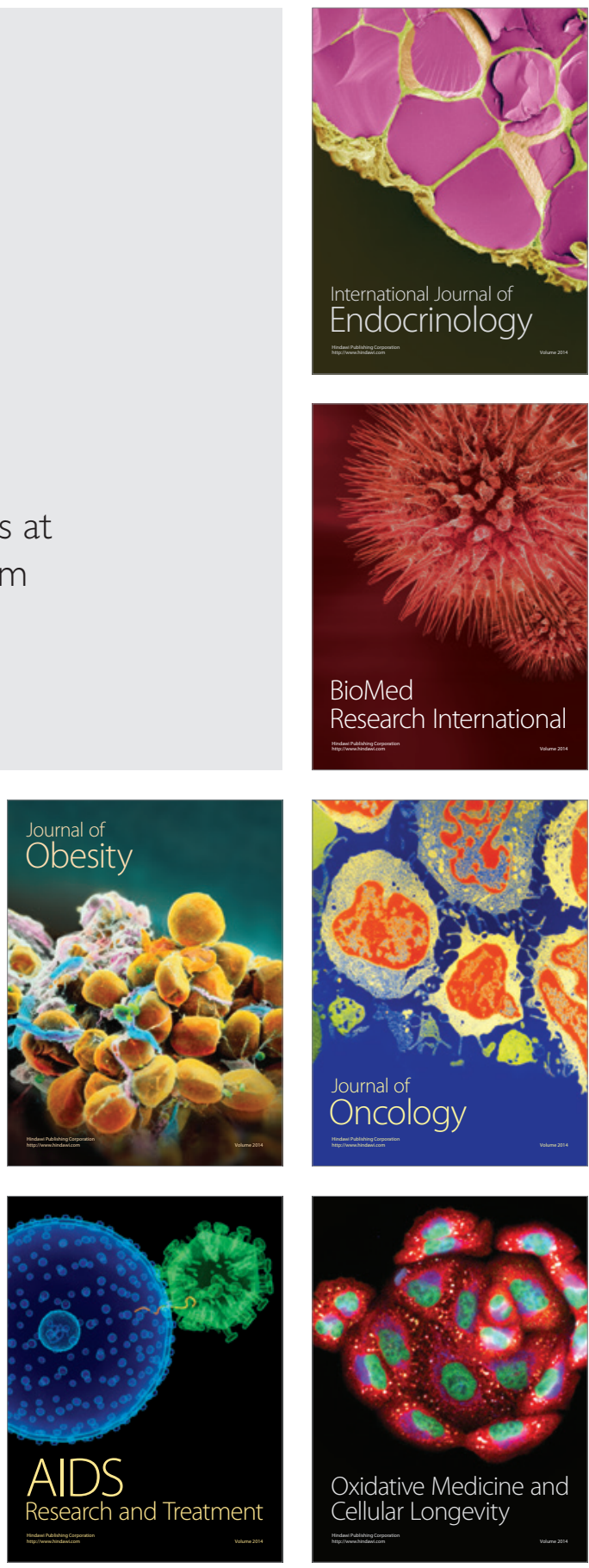